\title{
Innovative approach of consolidation of business, education and science to improve public catering of the Republic of Bashkortostan
}

\author{
Konstantin Alexandrovich Kuzminykh, and Guzel Garifullovna Mukhamatova \\ USPTU, Russian Federation, Ufa, 450078, Cosmonauts, 1
}

\begin{abstract}
This article discusses the problems and prospects of introducing innovative methods of consolidating the restaurant business, educational institutions in the field of restaurant service and current scientific research in order to improve the work of catering establishments in the Republic of Bashkortostan and achieve maximum convenience and speed in training staff. The article analyzes the problems, because of which such consolidations were not previously sufficiently popular and effective, argues the importance and need of modern Internet technologies and gadgets in creating such consolidations, and proves the effectiveness of online consolidations before similar offline options. Using a study and analysis of various instant messengers, their advantages and disadvantages * were identified, and a messenger was selected through which consolidation data will be organized in the most practical and accessible way. According to the results of the analysis, it turned out that the most effective and highly functional messenger for this kind of consolidation is Telegram, which is several fundamentally important points ahead of all its competitors. The article also discussed in detail the model of interaction between representatives of education and science on the one hand and business on the other. All formats and types of such cooperation are described.
\end{abstract}

\section{Introduction}

The search for and development of innovations in the field of catering is a very important part of the development of the industry. The development of products that solve the problems of their consumers quickly, easily, efficiently and profitably affect the entire industry as a whole and create conditions under which previously difficult processes by temporary and physical efforts become either fully automated or simply simplified, which makes it possible to save both temporary and financial resources. But at the moment, consolidations between science, education and business for a number of reasons are very weak. This also comes from a lack of understanding of the benefits of this kind of cooperation, in some cases it is caused by the inconvenience of organizing such events, in

\footnotetext{
${ }^{*}$ Corresponding author: muhamatovaguze14@gmail.com
} 
other cases it is a common lack of understanding of how and what tools to implement consolidation. It was these factors that were the main obstacles to the earlier creation of such innovations.

And the benefit, meanwhile, is absolutely obvious: for education and science, consolidation is revealed by the possibility of attracting resources for more effective functioning of institutions, as well as for practical exercises and an excellent field for developing new hypotheses and testing existing ones. For catering establishments, it is an opportunity to optimize all the processes taking place in institutions and with the help of experienced specialists, both in practical and theoretical terms, to achieve the most effective and successful functioning of institutions $[1-2]$. Such cooperation clearly has an excellent perspective and various modern technologies, in particular the Telegram messenger, due to its high functionality and convenience, can make it not only real, but also extremely popular and effective.

Therefore, this article will disclose the need for such consolidation, explain the benefits of each of the parties and explain how modern Internet technologies and gadgets can make such consolidation convenient, accessible and effective.

\section{Materials and Methods}

The study revealed many problems associated with the difficulties of developing consolidation between catering and education institutions in the virtual space. The main goal of this study is to develop innovative methods for solving development problems of this kind of consolidation. To achieve this goal, the article must answer the main questions, such as:

1. How do we see implementation consolidation in instant messengers?

2. Which of the instant messengers is the most suitable for the development of consolidations?

3. According to what schemes and rules will interaction take place between representatives of education and employees of institutions?

4. Why should such a consolidation format be interesting to both sides?

5. How will this innovation be promoted?

Object of study: the possibility of implementing consolidation in the cross-platform messenger Telegram.

Subject of the study: study of the properties and characteristics of the Telegram messenger.

Analysis of the study: The study of various scientific and practical articles revealed that today the consolidation between education, scientific research and business is approximately as follows:

- owners of catering establishments in the course of their own training and that of their employees may, including privately, contact the teachers of the necessary disciplines for consultation and professional evaluation;

- owners and employees may take part in various training activities organized by representatives of educational institutions. For example: exhibitions, congresses, online training events;

- owner of the institution can hire the necessary representative of the educational institution to work, thereby applying his experience and knowledge directly to his institution.

These consolidation methods are convenient for those catering establishments that are located in those cities where there are relevant educational institutions and departments. But they are far from everywhere and therefore catering establishments in small cities in which there are no relevant educational institutions, do not have the opportunity to seek help and 
knowledge from representatives of educational institutions, or this opportunity is given to them in a very uncomfortable and costly way.

In addition to the problem of the rather difficult availability of such consolidations for small cities where there are no appropriate educational institutions, there is a problem of their unpopularity, which is caused by a number of reasons:

1. Not all owners of establishments know that cooperation between them and representatives of education in this area generally exists and is accessible to them.

2. Excessive arrogance of owners who do not consider this kind of cooperation at least somehow useful. As a rule, these are institutions where more experienced employees teach less experienced on their own and without the involvement of professionals.

3. The absence of marketing activities on the part of representatives of education, thanks to which the owners of institutions could learn about the possibility of cooperation. Also, in cases where an intermediary is engaged in the organization of consolidation, the lack of targeted actions aimed at popularization on his part.

4. The format of such consolidations cannot be called as convenient and accessible as possible.

5. Private educational courses take almost all the traffic of those wishing to study.

As it turned out, today the consolidation between education and business in the field of public catering in the Republic of Bashkortostan is very poorly expressed and is carried out in an outdated, including moral format. And gadgets and Internet technologies have not yet had time to penetrate this area in order to make it more convenient and attractive for both business and education. Meanwhile, the format of online cooperation and education is gaining momentum and, as a result, the interaction between all parties becomes as simple and convenient as possible: with this format of cooperation, there is often no need to be present in any particular place, which solves the geographical problem and all the resulting difficulties; Training and consultations take place at a convenient time for everyone, and if there was no opportunity to participate, for example, in a webinar, you can always watch the recording and immediately ask questions; advice on difficulties can be obtained remotely, having only a smartphone and the Internet. Therefore, the implementation of such consolidations in online format through instant messengers can be considered really innovative. The following is a comparison of the most current and popular instant messengers in which it is possible to implement this innovation in order to identify the most suitable platform for creating consolidation, and an argument is given why the choice was made in favor of the Telegram messenger.

Table 1.Comparison of online instant messengers

\begin{tabular}{|c|c|c|}
\hline \begin{tabular}{|l} 
Messenger \\
\end{tabular} & Advantages & Disadvantages \\
\hline WatsApp & $\begin{array}{c}\text { Convenient and easy to use Have the ability to create } \\
\text { chats } \\
\text { Make group calls share files } \\
\text { Send video messages and voice messages } \\
\text { Ability to save Chat Content to cloud storage }\end{array}$ & $\begin{array}{c}\text { Intermittent Message Delivery Failures } \\
\text { Unable to Search for Thematic Channels and } \\
\text { Chats The security level is not the maximum } \\
\text { High level of spam Prevent faster playback of } \\
\text { files } \\
\text { Inconvenient use on a personal computer }\end{array}$ \\
\hline Viber & $\begin{array}{l}\text { Convenient and easy to use } \\
\text { Ability to create chats, make group calls, share files, } \\
\text { send video messages and voice messages The ability } \\
\text { to make calls to city and mobile numbers from the } \\
\text { application }\end{array}$ & \begin{tabular}{|c|} 
Poor Audio/Video Connectivity \\
Census history is not preserved \\
Poor spam protection \\
Voice messages can be recorded for a \\
maximum of 30 seconds \\
No ability to search for thematic channels and \\
chats \\
Security level is not maximum \\
No ability to speed up file playback \\
Inconvenient PC usage
\end{tabular} \\
\hline
\end{tabular}


Continuation of Table 1. Comparison of online instant messengers

\begin{tabular}{|c|c|c|}
\hline Instagram & $\begin{array}{c}\text { Good user engagement. } \\
\text { Mutual subscriptions and likes, so you can create } \\
\text { visibility of popularity. } \\
\text { Actively viewing stories. } \\
\text { Implementing Ads in Tape and Stories }\end{array}$ & $\begin{array}{l}\text { Some products cannot be fully imagined, and } \\
\text { users have to be redirected to another site, and } \\
\text { therefore there is a loss of traffic. } \\
\text { Strict rules, so because of any trifle can block } \\
\text { Limited Chat Capabilities } \\
\text { Group videos and voice calls cannot be made }\end{array}$ \\
\hline Вконтакте & $\begin{array}{l}\text { The most visited social network in Russia. } \\
\text { Extensive functionality. } \\
\text { Traffic does not fall, as it is possible to talk in detail } \\
\text { about the service in the social network itself, without } \\
\text { taking its active user out of the comfort zone. }\end{array}$ & $\begin{array}{c}\text { Event or news search is not working well } \\
\text { Screwed tags do not fix situations } \\
\text { Wasteoftime } \\
\text { Safety }\end{array}$ \\
\hline Telegram & $\begin{array}{l}\text { Ability to create chats, make group calls, share files, } \\
\text { send video messages and voice messages without a } \\
\text { limit } \\
\text { Ability to store chat content in cloud storage } \\
\text { Open source, which allows you to adapt the } \\
\text { application to yourself } \\
\text { The most convenient chat. You can contact a specific } \\
\text { person, and they will receive a notification about it. } \\
\text { You can use it on several devices at the same time } \\
\text { Easy to use on a PC } \\
\text { Ability to speed audio and video playback } \\
\text { Maximum security } \\
\text { Availability of convenient search of various materials } \\
\text { and thematic channels } \\
\text { The most pleasant of all the listed messengers design } \\
\text { and the possibility of creating thematic stickers }\end{array}$ & \\
\hline
\end{tabular}

Thus, we can conclude that Telegram has advantages over other messengers in a number of really important indicators, and therefore the organization of innovative consolidation between education and business is proposed there.

\section{Result and discussion}

As an example, a chat is given in the Telegram messenger, where the consolidation between the owners and employees of institutions on the one hand and the teachers of the Department of Tourism of the Hotel and Restaurant Service (DTHRS) of the USPTU is as follows:

- opportunity to communicate, share experiences, ask for advice and ask any thematic questions between all participants (owners and employees of institutions);

- opportunity to ask a question and explain any situation with the specialist personally. Depending on the selected package of services, the consultation can take place either in correspondence format, or in video communication format, or in person;

- thematic videoconferences in which the specialists of the Department of (DTHRS) of the USPTUwill share some useful information with the rest of the chat;

- announcements of various training events organized by teachers. Depending on the package chosen, representatives of catering establishments will have access to courses and events of various levels of value;

- informational and training articles with thematic content, which are educational in nature. For example, an article on new table serving trends, etc.;

- participation in various surveys in order to identify the necessary statistical data and further their introduction by business representatives into their own institutions; 
- possibility to agree on the departure of the specialist to the institution in order to analyze it and train the staff. The service will be available to the owners of the largest service package [3].

In general, the creation of such a chat can serve to improve the theoretical and practical qualifications of owners and staff of catering establishments, makes it possible to call the right specialist to the institution, makes it possible to learn, be aware of innovations, new trends, and in general fill gaps in the theoretical and practical understanding of the activities of catering establishments. It is also important to note that the principle of consolidation work includes, if necessary, individual work with the necessary specialists, when each participant has the right to contact the chat worker with his or her own individual problem, question and/or task.

This consolidation format is useful in that both parties can maintain regular communication and often without the need for off-line presence. In the same way, concluding its innovative essence: the development of communications and Internet technologies allows previously complex and costly processes in all plans to be made more mobile, convenient and accessible, which was previously simply impossible on a massive scale.

It is also important to elaborate on another advantage of this method: traditional methods of training owners and employees of catering establishments in the form of various courses, webinars, etc. are not popular due to their high cost, length of training and inconvenience, which is expressed in numerous details. While the described format solves all the same problems cheaper, and under more convenient conditions, and often in more convenient and individually selected time frames [4 - 5].

The organizers of such consolidation can be both people who are intermediaries between business and education, that is, act only as a link in order to earn and provide convenience to the parties, and the representatives of education themselves, that is, teachers of the department of (DTHRS) of the USPTU. The organizers should pay special attention to the selection of specialists, since when buying participation in the consolidation, business representatives should be able to address any question and receive mobile full, qualified assistance and close all their needs [6]. In other words, specialists should be selected so that business representatives can get the full cycle of services they need to solve the difficulties that arise in their institutions.

As for the cost of participating in such consolidation for the owners and employees of the institution, it is necessary to develop several packages so that everyone receives from this interaction exactly what his institution needs.

The price category was set according to several parameters:

- analysis of price policies of similar projects;

- economic feasibility;

- survey of education representatives on the desired income;

- identification of approximate financial capabilities of clients;

- survey of owners of establishments to determine their needs and how much they are willing to pay for consolidation;

- a favorable offer against the background of competitors;

- calculation of fixed costs.

Package No. 1 "Initial": access to the chat without the possibility of contacting personal specialists. Access is given to all mass content and group online meetings. The cost of 11,900 rubles per month. For this cost, only the owner gets access. The most basic package is suitable for those institutions that already work in plus and need only rare advice and fresh, up-to-date information from the world of catering.

Package No. 2 "Advanced": access to a chat with the ability to contact specialists with personal questions up to five times a month. In addition to mass content, package owners 
get access to closed events of increased information value and subscription to methodological support. The cost is 28,900 rubles per month. For this cost, access is given to the owner and administrators to choose from. It is suitable for those institutions in which periodic difficulties occur that the owner and managers are not able to cope with on their own.

Package No. 3 "Maxi": access to everything previously listed, unlimited access to specialists and the possibility of calling a specialist to the institution 1 once a month. Cost 59900p. For this cost, access is obtained by the owner and all employees. This package is designed for those institutions that require radical changes.

Innovation Promotion Plan: In order to massively convey this idea to the owners and managers of institutions, the following promotion strategy is proposed:

1) Compilation of the base of contacts of institutions from open sources: sites, social networks, aggregators. Next is a cold call to the database, which will offer a free demo version of the product, based on the results of which owners will decide to buy. Before paying, customers must have time to use the product.

2) Organization of an open day in the online format and also in the cold call mode, an invitation to managers and owners to participate in it. As part of this event, the main problems facing the catering market at the moment will be voiced and this innovation will be presented as a decisive tool for these problems. This event can also be held offline.

3) Presentation of the product at thematic exhibitions and forums.

4) Buying ads on thematic blogs.

5) Create an automated sales funnel with an autovebinar.

6) Offline advertising in the form of billboards and advertising on thematic platforms.

\section{Conclusions}

The development of innovative products, including in the field of consolidation at the intersection of business, education, science and modern technologies, is an extremely important activity that benefits each of the parties. For business, this is an opportunity for convenient training in order to optimize the processes of institutions and their maximum effective functioning, for education - an influx of funds and practice, for science - an experimental base and good conditions for testing and introducing various hypotheses [7 8].

The study concludes that the problem of consolidating business and education is caused by a lack of understanding of the need for cooperation between the parties, as well as a lack of mechanisms, convenience and mobility that take into account the interests of participants and mechanisms through which interested participants can actively express their positions on the issues of concern. To solve this problem, measures have been proposed to develop a channel/chat plan in the Telegram messenger, which will increase the efficiency of the research and development sector, optimize business processes, which in turn will take into account the diverse needs of the represented groups and in the future carry out effective coordination at all levels.

\section{References}

1. V. Bol'shakova, N. G. Kopasovskaya, Vestnik SAMGUPS, 4 (2017)

2. M.DeSanktis, A. Bukkiarone, A.Markoni, InternetServAppl, 11 (2020)

3. A. D. Ivanov, VestnikVuiT, 3 (2016)

4. T.I. Kazakova, I.Yu. Popova, ANI Economics and Management, 1 (2015) 
5. Yu V. Malahova, R. V. Krylova, Investment and innovation, 21 (2014)

6. K. A. Kuz'minyh, Bulletin of Samara State Economic University, 7 (2011)

7. K. A. Kuz'minyh, Ufa: Ufa State Academy of Economics and Service, (2012)

8. O. V. Nazarov, How to "promote" the restaurant. Restaurant lists: textbook 